\title{
PRODUÇÃO DE FORRAGEM E VALOR NUTRITIVO DE FLUVA SOB INTERVALOS DE CORTE
}

\section{FORAGE PRODUCTION AND NUTRITIONAL VALUE OF SWEET VERNAL GRASS UNDER CUTTING INTERVALS}

\author{
Ana Lúcia HANISCH ${ }^{1}$ \\ Ulisses de Arruda CÓRDOVA ${ }^{2}$ \\ Ângela Fonseca $\mathrm{RECH}^{3}$ \\ José Lino ROSA ${ }^{2}$
}

\begin{abstract}
RESUMO
O experimento foi conduzido em campo, em uma pastagem de fluva (Anthoxantum odoratum L.) formada há um ano, com o objetivo de avaliar o efeito de diferentes intervalos de corte na produção de massa seca e valor nutritivo do pasto. Foi utilizado delineamento experimental em blocos casualizados, com quatro repetições e quatro tratamentos de intervalos entre corte $\left(28,35,42\right.$ e 49 dias). Foram aplicados $140 \mathrm{~kg} \mathrm{ha}^{-1} \mathrm{ano}^{-1}$ de nitrogênio, na forma de uréia, em todos os tratamentos e o pasto foi cortado a uma altura de $7 \mathrm{~cm}$ do solo. Foram realizados 12, 10, 8 e 7 cortes, respectivamente, para os intervalos de $28,35,42$ e 49 dias. A produção de massa seca reduziu de forma quadrática $(P<0,002)$ com o aumento de dias no intervalo entre cortes. O teor de proteína bruta decresceu de forma linear $(P<0,02)$ e a digestibilidade in vitro da matéria orgânica decresceu de forma quadrática $(P<0,002)$ com o aumento dos intervalos entre cortes. $O$ intervalo de cortes de 35 dias proporcionou a melhor combinação entre produção de massa seca de forragem e melhor valor nutritivo, sendo indicado para manejo sob cortes para Anthoxanthum odoratum L.
\end{abstract}

Palavras-chave: fluva; freqüência de cortes; pastagem; perenes de inverno

\begin{abstract}
The experiment was carried out in a field with the objective to evaluate the influence of cutting intervals on dry mass production and nutritional value of Anthoxantum odoratum. Treatments were arranged in a randomized complete blocks design with four replications. The treatments were constituted by four cutting intervals (28, 35, 42 and 49 days). After cuttings, at a distant $7 \mathrm{~cm}$ from soil, $140 \mathrm{~kg} / \mathrm{ha}$ of $\mathrm{N}$, in the urea form, was applied to all treatments. Twelve cuttings were carried out at 28 day-intervals, ten at 35 day-intervals, eight at 42 day-intervals and seven at a 49 day-interval. The dry matter yield decreased quadratically $(P<0.002)$ with increasing the interval between cuts. The crude protein content decreased linearly $(P$ $<0.02)$ and in vitro digestibility of organic matter decreased quadratically $(P<0.002)$ with increasing intervals between cuts. The cutting interval of 35 days provided the best combination of dry matter yield and forage nutritive value and is indicated for management in cuts to Anthoxantum odoratum L.
\end{abstract}

Keywords: fluva, cutting frequency, pasture, perennial winter pasture

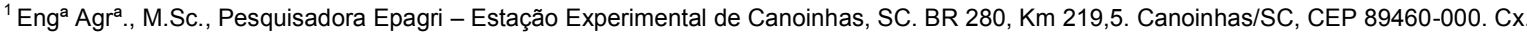
Postal 216. Fone 473624 1144. E-mail: analucia@epagri.sc.gov.br

${ }^{2}$ Eng. Agr., M.Sc., Pesquisador Epagri - Estação Experimental de Lages, SC. E-mail: ulisses@epagri.sc.gov.br; joselino@epagri.sc.gov.br;

${ }^{3}$ Zootecnista; M.Sc. Pesquisadora Epagri - Estação Experimental de Lages, SC. E-mail: angelarech@epagri.sc.gov.br
} 
HANISCH, A.L. et al. Produção de forragem e valor nutritivo...

\section{INTRODUÇÃO}

Devido às condições edafoclimáticas favoráveis para o uso de pastagens como volumoso para o rebanho bovídeo no Brasil, observa-se uma constante busca de novas espécies e cultivares forrageiras destinadas ao pastejo que apresentem elevado valor nutritivo e boa adaptação ao clima de determinada região. Na maior parte da região Sul, devido ao inverno rigoroso, grande parte das espécies de forrageiras perenes de verão cessam seu crescimento por vários meses, gerando significativa demanda por pesquisas com forrageiras de clima temperado. Apesar da existência de diversas espécies com potencial de uso para regiões frias, de um modo geral, há poucos trabalhos com forrageiras perenes de inverno no Brasil, em especial, trabalhos relacionados ao manejo dessas espécies (SchefferBasso et al., 2002; Hanisch et al., 2011). Hanisch et al. (2010) avaliando cinco diferentes espécies de forrageiras perenes de inverno (festuca, bromus, faláris, aveia-perene e dactilo) em clima Cfb, verificaram em comum à todas as espécies, a excelente qualidade da forragem e a dificuldade de persistência por mais de dois anos na mesma área.

A fluva (Anthoxanthum odoratum L.) é uma gramínea perene de clima temperado, de origem européia, que foi cultivada, experimentalmente em diversas estações experimentais há algumas décadas, em regiões de maior altitude no Sul do Brasil (Araújo, 1942). Caracteriza-se por um pronunciado aroma que desprende, devido à presença, sobretudo, na região dos nós do colmo, de um princípio ativo: a cumarina. Uma referência sobre essa espécie foi relatada por Runciman et al. (2002), sobre o efeito tóxico da cumarina presente na silagem de fluva, responsável pela morte de vacas leiteiras. Quando utilizada como forragem verde para pastejo não foram encontradas referências de toxidez ou distúrbio em bovídeos.

Referências sobre seu comportamento produtivo são registradas com maior frequência em estudos sobre pastagens naturais em países europeus, especialmente associada à outras perenes de inverno como Phalaris arundinacea ou festucas (Molofsky et al., 1999; Pontes et al., 2007). No entanto, existe considerável escassez de informações sobre sua ecofisiologia, que permitam direcionar práticas sustentáveis de manejo para essa espécie em cultivo. Resultados de avaliações em unidades experimentais citam a sua tolerância ao sombreamento e capacidade de produzir forragem nessa condição e durante invernos rigorosos (Otero, 1961; Araújo, 1971).

A determinação de indicadores de manejo para cada espécie forrageira pode assegurar alta produção de matéria seca, alto valor nutritivo e persistência da pastagem. Neste contexto, a avaliação do efeito de intervalo entre cortes é muito importante. Em geral, quanto maior o intervalo entre cortes maior a deposição de material fibroso, diminuição do valor nutritivo e do consumo. Porém, quando o intervalo entre cortes é muito pequeno ocorre redução na produção de forragem e nas reservas das plantas, afetando o potencial de rebrota. Segundo Raymond (1969) conforme a planta forrageira cresce, sua produção aumenta, mas seu valor nutritivo tende a decrescer; portanto a determinação do estádio ótimo de utilização da mesma requer a associação de dados sobre produção em diferentes estádios de maturidade e de parâmetros de valor nutritivo (Vieira et al., 1999). Como indicadores de qualidade podem ser utilizados os teores de PB, fibra e DIVMO (digestibilidade in vitro da matéria orgânica) das forrageiras.

O objetivo deste trabalho foi avaliar o efeito do intervalo entre os cortes sobre a produção de massa seca, altura, valor nutritivo e digestibilidade de fluva, obtendo-se assim informações que contribuam para a utilização eficiente desta forrageira.

\section{MATERIAL E MÉTODOS}

O experimento foi conduzido na Estação Experimental da Epagri de Canoinhas, na região do Planalto Norte Catarinense, localizada a $26^{\circ} 22^{\prime} \mathrm{S}$ e $50^{\circ} 16^{\prime} \mathrm{W}$, altitude de $800 \mathrm{~m}$ e clima Cfb. O solo da área experimental é classificado como Latossolo Vermelho Distrófico (Embrapa, 2006) e apresentava na ocasião da implantação do experimento, as seguintes características: $330 \mathrm{~g} \mathrm{~kg}^{-1}$ de argila; $\mathrm{pH}_{\text {água }}=$ 6,$0 ; \mathrm{P}=3,8 \mathrm{mg} \mathrm{dm}^{-3} ; \mathrm{K}=400 \mathrm{mg} \mathrm{dm}^{-3} ; \mathrm{MOS}=42 \mathrm{~g}$ $\mathrm{dm}^{-3} ; \mathrm{Ca}=10,4 \mathrm{cmol}_{\mathrm{c}} \mathrm{dm}^{-3}$; saturação de bases $=$ $72,39 \%$. Antes da semeadura da fluva, o solo foi previamente corrigido e adubado de acordo com a recomendação para gramíneas perenes de inverno (CQFS-RS/SC, 2004).

A pastagem de Anthoxanthum odoratum genótipo naturalizado coletado no município de Painel, SC - foi semeada na área experimental em maio de 2008, utilizando-se $10 \mathrm{~kg} \mathrm{ha}^{-1}$ de sementes, e permaneceu em crescimento vegetativo, sem cortes, até março de 2009 , quando sofreu um corte de uniformização e foi adubada de acordo com a recomendação para gramíneas perenes de inverno (CQFS-RS/SC, 2004). Os cortes para avaliação ocorreram no período de maio de 2009 a março de 2010. As temperaturas médias e a precipitação do período estão apresentadas na Figura 1. 
HANISCH, A.L. et al. Produção de forragem e valor nutritivo...

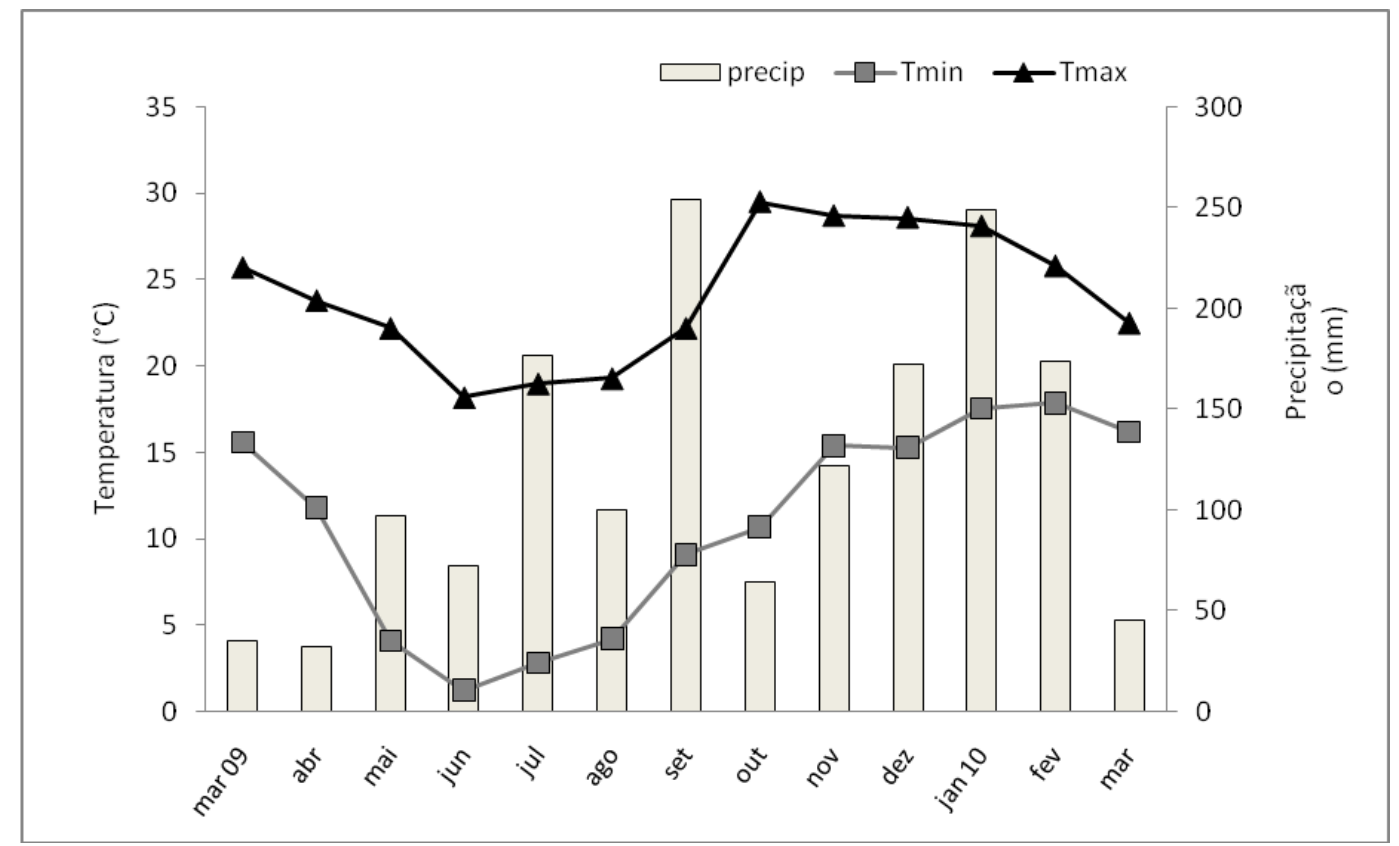

Figura 1 - Somatória da precipitação mensal e média das temperaturas mínimas e máximas na área experimental. Canoinhas, SC. Fonte: Ciram/MDA Fruplanorte.

O delineamento utilizado foi o de blocos casualizados, em parcelas subdivididas no tempo, alocando-se nas parcelas os tratamentos e nas subparcelas as datas de cortes, com quatro repetições. Os tratamentos constituíram de quatro intervalos de corte: $28,35,42$ e 49 dias, totalizando 16 parcelas, sendo que cada parcela media $6 \mathrm{~m}^{2}$ e possuía área útil de $4 \mathrm{~m}^{2}$.

Foi avaliada a produção de massa seca (MS), através de cortes realizados com o auxílio de quadros de $1 \mathrm{~m}^{2}$ lançados aleatoriamente na área útil da parcela, cortados a uma altura de $7 \mathrm{~cm}$ do solo. Após cada corte, toda a parcela foi roçada, o material retirado da mesma e foi aplicado nitrogênio $(\mathrm{N})$, na forma de ureia. As doses de $\mathrm{N}$ por tratamento foram calculadas, dividindo-se a dose de $140 \mathrm{~kg}$ $\mathrm{ha}^{-1}$ ano $^{-1}$ de $\mathrm{N}$, pelo número de cortes a serem realizados no período de avaliação para cada intervalo de cortes.

A pastagem cortada foi pesada e retirado uma subamostra, que foi seca em estufa com circulação de ar, a $65^{\circ} \mathrm{C}$ até massa constante, para determinar o teor de matéria seca (MS). Para estimar a altura do stand foi utilizada régua graduada em 5 pontos representativos de cada parcela. Considerou -se como a altura da superfície do pasto, o local em que a régua graduada tocava na extremidade e/ou no ponto de curvatura da lâmina da folha, a partir do nível do solo.

Foram realizadas análises bromatológicas, em amostras compostas de cada tratamento. As amostras compostas foram encaminhadas para as análises dos teores de MS, matéria orgânica (MO), proteína bruta (PB), fibra detergente ácido (FDA) e fibra em detergente neutro (FDN), realizadas segundo metodologia descrita por Silva \& Queiroz (2002). A análise da digestibilidade in vitro da matéria orgâ- nica (DIVMO) foi executada segundo Tilley \& Terry (1963) e os teores de nutrientes digestíveis totais (NDT) foram estimados de acordo com a fórmula: \% NDT $=\%$ DIVMO * \% MO / 100.

Os dados coletados foram submetidos à análise de variância e teste F com o auxílio do programa estatístico Sisvar. Quando constatados efeitos significativos dos tratamentos, foi realizada análise de regressão polinomial, sendo escolhidos os modelos que melhor se ajustaram ao fenômeno investigado. Utilizou-se o nível de $5 \%$ de probabilidade de erro.

\section{RESULTADOS E DISCUSSÃO}

Foram realizados doze, dez, oito e sete cortes ao longo do ano, respectivamente, para os intervalos de $28,35,42$ e 49 dias e não foi verificado efeito dos tratamentos sobre a altura da pastagem (Tabela 1), que permaneceu, em média, com $18 \mathrm{~cm}$ de altura. Apesar de não terem sido encontrados outros registros de altura de fluva, infere-se que o fato das plantas manterem alturas tão próximas entre os tratamentos, independentemente de intervalos de cortes distantes entre si mais de 20 dias, se deve em parte, ao seu hábito de crescimento prostado onde as folhas tendem a permanecer próximas ao solo.

A produção de massa seca total reduziu de forma quadrática $(P<0,002)$ com o aumento de dias no intervalo entre cortes (Figura 2). O intervalo entre cortes de 35 dias promoveu a maior produção, de $6.789 \mathrm{~kg} \mathrm{ha}^{-1}$. Os resultados observados para este intervalo foram próximos aos valores de 6.000 a $8.000 \mathrm{~kg} \mathrm{ha}^{-1}$ de forragem seca para esta espécie, citados por Araújo (1971). 
HANISCH, A.L. et al. Produção de forragem e valor nutritivo...

Tabela 1- Número de cortes/ano e altura média em plantas de fluva (Anthoxanthum odoratum) submetida a quatro intervalos de corte. Canoinhas, SC. 2010.

\begin{tabular}{ccc}
\hline Intervalo corte & $\mathrm{N}^{\circ}$ cortes/ano & Altura $(\mathrm{cm})$ \\
\hline 28 dias & 12 & $17,5 \mathrm{a}$ \\
35 dias & 10 & $18 \mathrm{a}$ \\
42 dias & 8 & $19 \mathrm{a}$ \\
49 dias & 7 & $19,5 \mathrm{a}$ \\
\hline C.V. $\%$ & & 10,6
\end{tabular}

Médias seguidas por letras diferentes nas colunas diferem entre si pelo teste de Tukey a $5 \%$ de probabilidade. C.V. = coeficiente de variação.

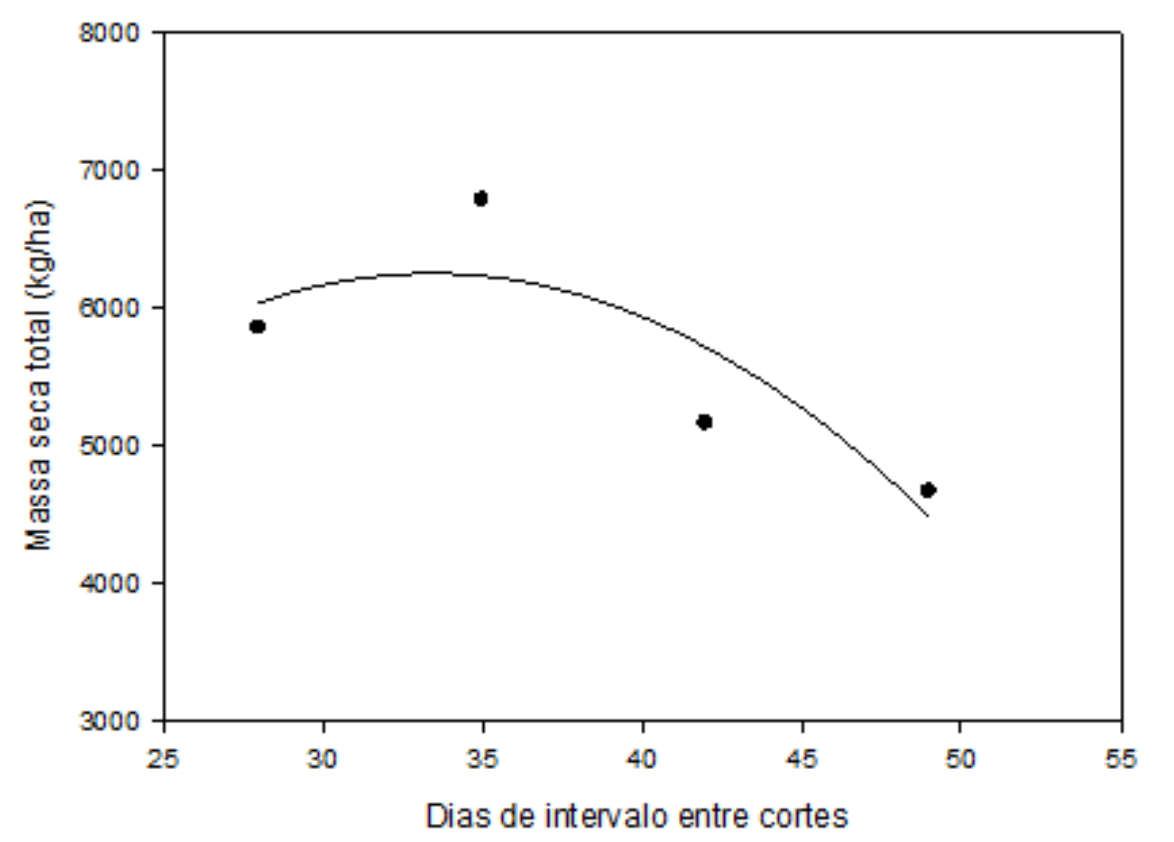

Figura 2 - Produção de massa seca total de fluva (Anthoxanthum odoratum L.) submetida a quatro diferentes intervalos de corte $(28,35,42$ e 49 dias). Canoinhas, SC. 2009/10.

O intervalo entre cortes de 35 dias permitiu uma distribuição mais homogênea da produção de massa seca ao longo dos meses, prolongando o ciclo produtivo da fluva até o mês de dezembro (Figura 3). Por outro lado, o maior intervalo entre cortes, de 49 dias, proporcionou maiores produções de forragem nos três primeiros cortes, mas essa característica permaneceu apenas até o corte realizado no mês de outubro. A partir dessa data, nos meses seguintes a produção acumulada estabilizou, indicando que cortes em intervalos mais longos, contribuem para a redução do período de produção de MS da fluva (Figura 3). 
HANISCH, A.L. et al. Produção de forragem e valor nutritivo...

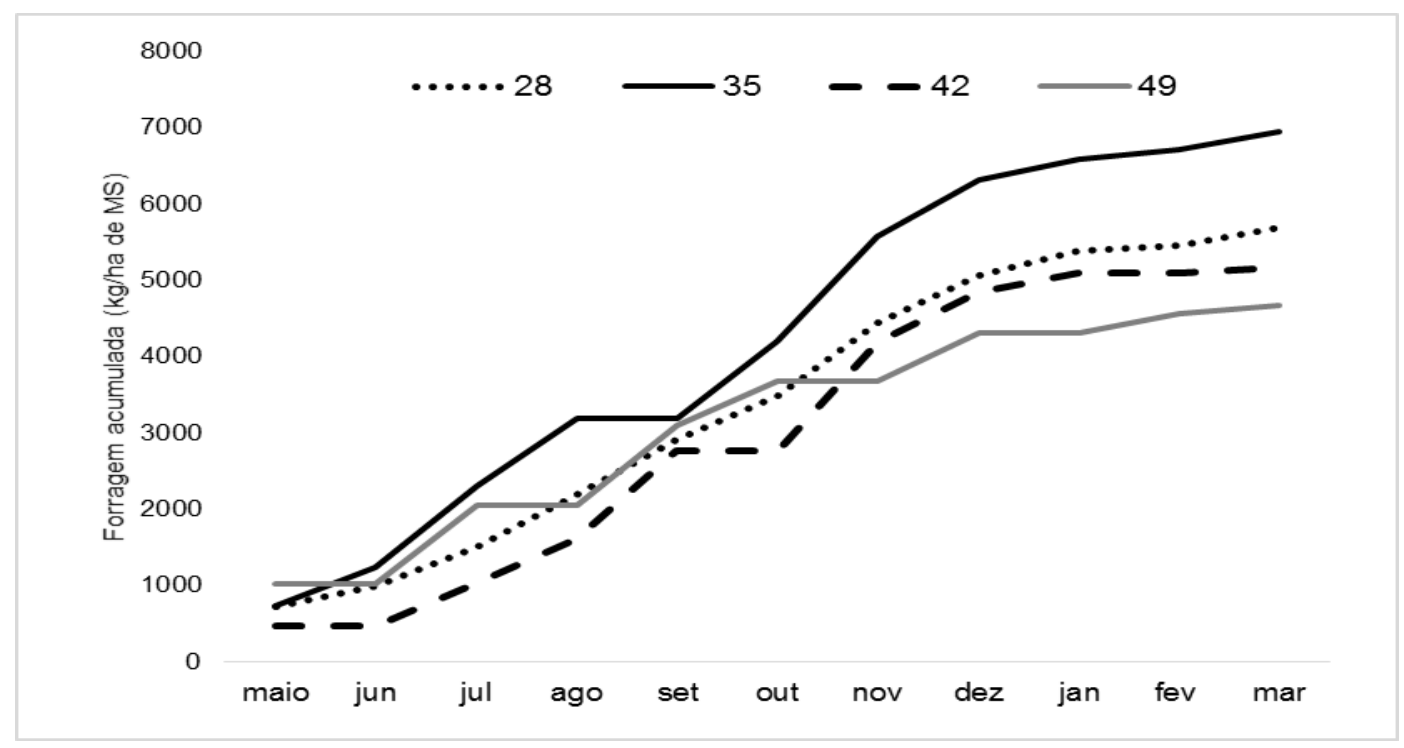

Figura 3 - Massa seca de forragem de fluva (Anthoxanthum odoratum L.), acumulada ao longo do ano, em quatro diferentes intervalos de corte (28, 35, 42 e 49 dias). Canoinhas, SC. 2009/10.

A redução da produção total de massa seca da forragem com o aumento dos intervalos entre cortes, observada neste trabalho, difere de outros autores que observaram aumento da produção de massa seca, com o aumento dos intervalos entre cortes em tanzânia (Souza et al., 2007), braquiária (Costa et al., 2007) e Bromus auleticus (Scheffer-Basso et al., 2009). No trabalho com bromus - que é uma espécie perene de inverno semeIhante à fluva - as avaliações foram por um curto período (3 meses) e os resultados foram semelhantes ao observado neste trabalho nos primeiros 3 cortes. No entanto, com o prolongamento do período de avaliação (de maio a março) foi possível verificar que ao longo do tempo, esse manejo de maior intervalo entre os cortes, foi prejudicial para a produção de MS em fluva.

Sabe-se que a redução das taxas de crescimento das plantas ocorre devido ao sombreamento progressivo das folhas inferiores, tornando-as menos efetivas fotossinteticamente (Corsi \& Nascimento Júnior, 1994). Se a espécie forrageira tem hábito de crescimento prostrado, como é o caso da fluva, o desenvolvimento de folhas novas ocorrerá em um ambiente de baixa intensidade luminosa. Assim, folhas que se desenvolvem em ambiente de baixa intensidade luminosa apresentam menor eficiência fotossintética que aquelas que se desenvolvem sem sofrer competição por luz. Além disso, períodos mais longos de crescimento levam ao aumento da taxa de senescência das folhas em relação à síntese de folhas mais novas (Viera et al., 1999).

Da Silva \& Pedreira (1997) avaliando três espécies forrageiras, alfafa (Medicago sativa L.), trevo branco (Trifolium repens L.) e Phalaris arundinacea (L.), observaram que plantas com predominância de folhagem remanescente apical cresceram mais rapidamente que plantas com folhagem predominantemente basal, ou seja, com folhas mais veIhas. Demonstraram ainda que, plantas de T. repens com folhagem com idade de 1 a 2 semanas produziram mais matéria seca e absorveram mais $\mathrm{CO}_{2}$ do que plantas com folhas de 3 a 4 semanas de idade. Com isso, os autores concluíram que a idade da folha e, consequentemente, sua eficiência, é um fator de extrema importância quando a proposta de manejo visa aumentos de produtividade.

O teor de proteína bruta diferiu entre os intervalos de cortes e decresceu linearmente $(P<0,02)$ com o aumento da idade da planta (Figura 4). Vários outros autores observaram redução nos teores de proteína com o aumento no intervalo entre cortes de forrageiras (Drudi \& Favoretto, 1985; Santos, 2009; Costa et al, 2007). No entanto, apesar da redução dos teores observados com o aumento dos intervalos entre cortes, a fluva apresentou teores elevados de proteína bruta para planta inteira, com valores médios que oscilaram de $17,5 \%$ a $15 \%$, respectivamente para intervalos de 28 e 42 dias. No entanto, todos os valores foram superiores a $15 \%$ de proteína bruta, o que indica adequado valor nutritivo para essa forrageira. A redução no teor de PB é explicada pelo maior envelhecimento da forragem disponível, associado à maior fração de forragem senescente, maior proporção de colmos com considerável desenvolvimento de tecidos estruturais (Macari et al., 2006). Eram esperados teores mais elevados de proteína bruta em intervalos de corte menores, pela maior porcentagem de folha em relação ao caule. O intervalo de 35 dias não diferiu do intervalo de 28 dias, apresentado teor de $17,3 \%$ de PB. Esses resultados indicam que a dose de $\mathrm{N}$ utilizada de $140 \mathrm{~kg} \mathrm{ha}^{-1}$ proporcionou produção de massa seca com valor nutritivo adequado. 
HANISCH, A.L. et al. Produção de forragem e valor nutritivo...
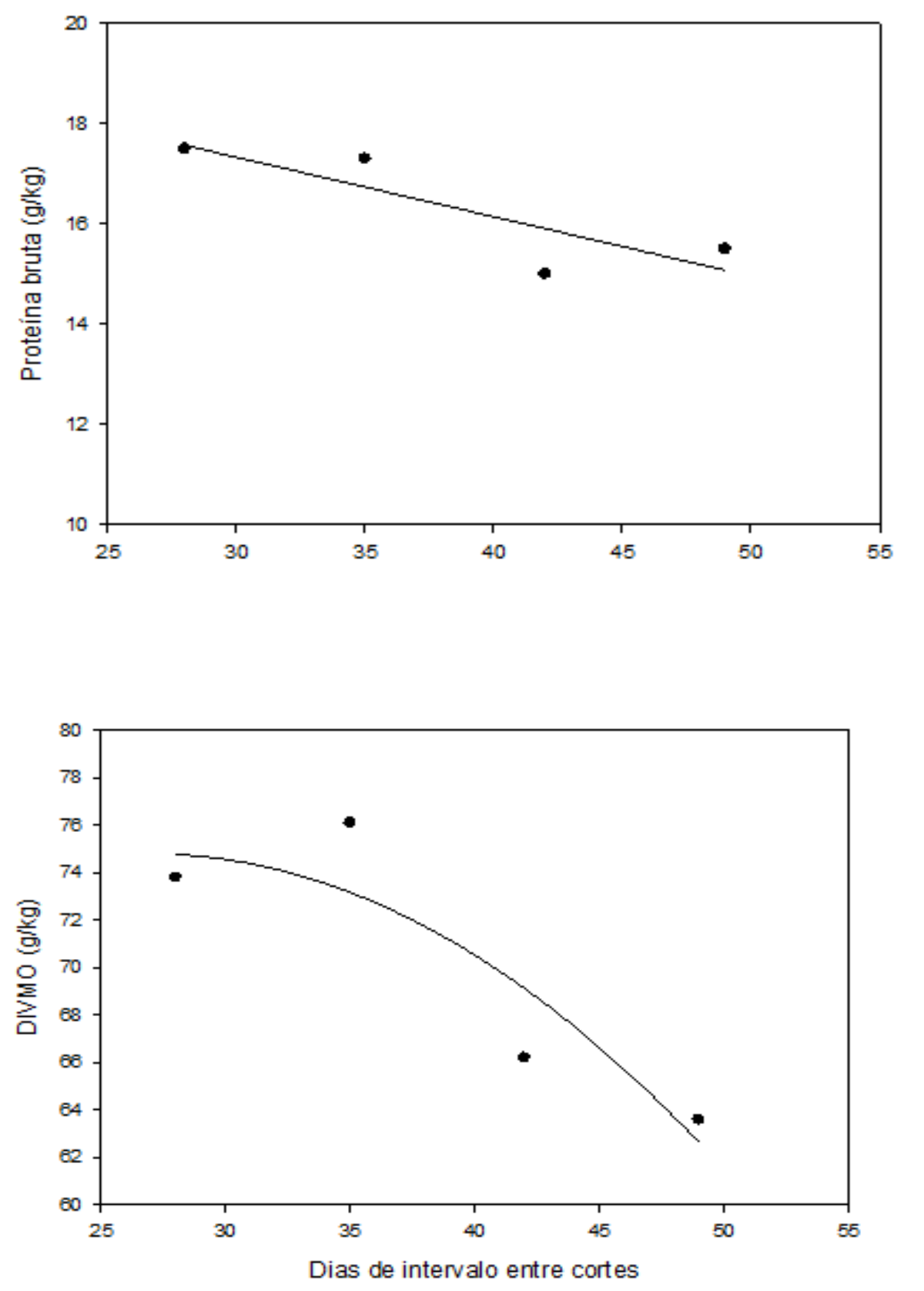

Figura 4 - Teor de proteína bruta e digestibilidade in vitro da matéria orgânica (DIVMO) de fluva (Anthoxanthum odoratum L.) submetida a quatro diferentes intervalos de corte (28, 35, 42 e 49 dias). Canoinhas, SC. 2009/10. 
HANISCH, A.L. et al. Produção de forragem e valor nutritivo...

Os valores máximo e mínimos de DIVMO foram observados respectivamente, aos 35 dias (761 g/kg) e aos 49 dias (663 g/kg). A digestibilidade in vitro da matéria orgânica apresentou a mesma tendência da proteína bruta com redução do teor à medida que aumentavam os dias de intervalo entre cortes (Figura 4). O modelo de regressão que meIhor se ajustou a esse comportamento foi o quadrático, uma vez que até os 35 dias de intervalo entre cortes, houve um aumento no teor de DIVMO. Esse decréscimo deve-se ao aumento no conteúdo de parede celular (o que pode ser observado pela crescente concentração de FDN, conforme Figura 5), associado, provavelmente, a um aumento na lignificação da mesma (Vieira et al., 1999).

Os teores máximos de FDN e FDA foram observados no intervalo de 49 dias entre cortes
(508 g/kg e $270 \mathrm{~g} / \mathrm{kg}$, respectivamente, para FDN e FDA). Houve ajuste quadrático no comportamento dos teores dessas variáveis (Figura 5), uma vez que aos 35 dias, o pasto apresentou teores de fibras um pouco menores que aos 28 dias, decorrente provavelmente do crescimento de folhas observado neste período, o que pode ser observado com o maior valor de massa seca avaliado com este intervalo entre cortes. Os teores de FDA e FDN observados em todos os tratamentos contribuíram para demonstrar a qualidade da forragem de fluva, uma vez que mesmo os maiores teores observados, atendem aos requisitos de alta qualidade de forragem. Os resultados da DIVMO acima de $62 \%$, PB acima de $15 \%$ e FDN abaixo de $55 \%$ indicam um excelente potencial para a utilização da fluva como forrageira.
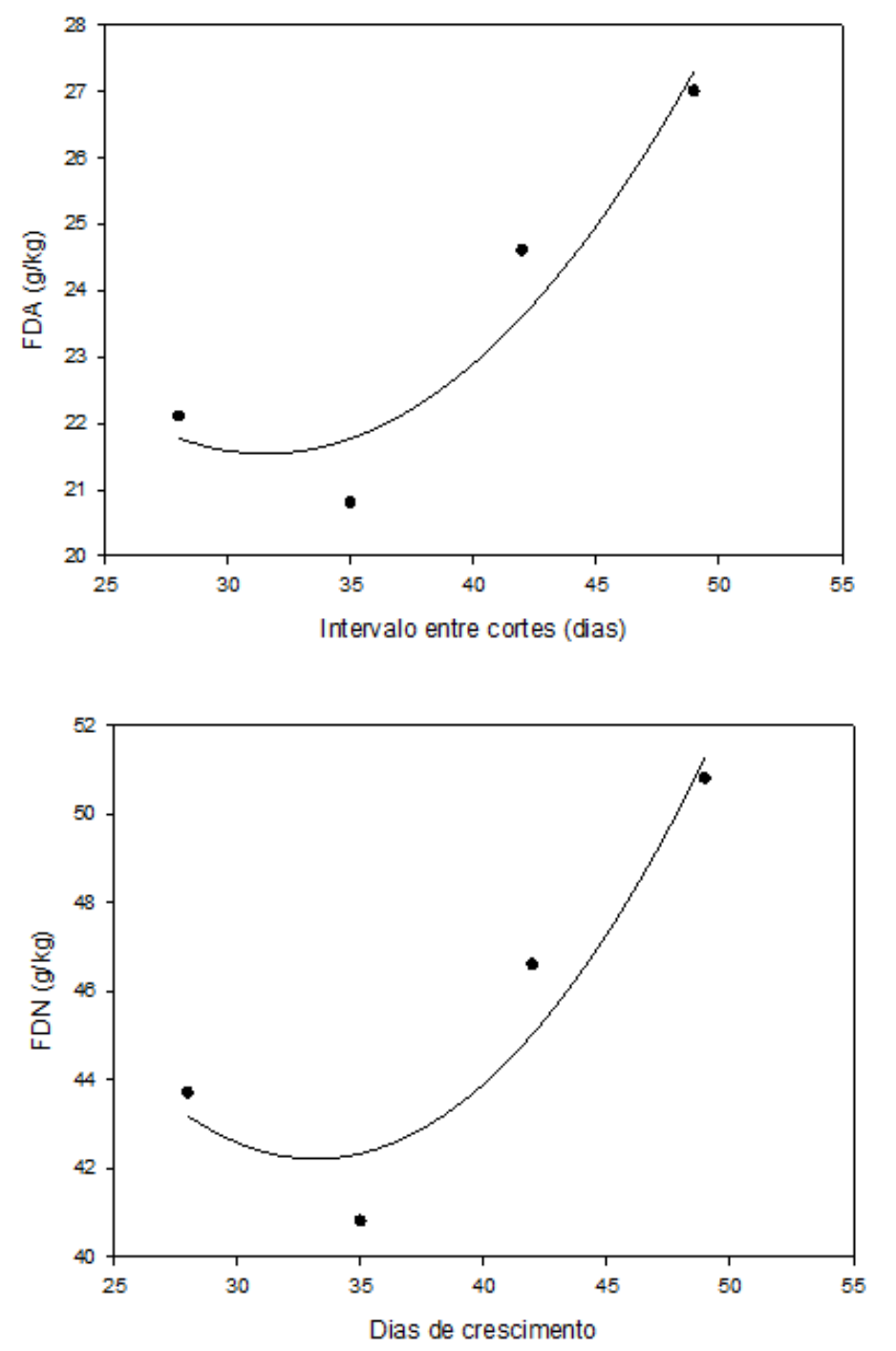

Figura 5 - Teores de fibra em detergente neutro (FDN) e fibra em detergente ácido (FDA) de fluva (Anthoxanthum odoratum L.) submetida a quatro diferentes intervalos de corte $(28,35,42$ e 49 dias). Canoinhas, SC. 2009/10. 
HANISCH, A.L. et al. Produção de forragem e valor nutritivo...

\section{CONCLUSÕES}

Nas condições avaliadas, recomenda-se intervalo de cortes de 35 dias para a espécie Anthoxanthum odoratum L., pois proporcionou ao longo do ano, maior produção de forragem e melhor valor nutricional.

Em função dos resultados obtidos, a fluva mostrou potencial para produção na região do Planalto Norte Catarinense, indicando a necessidade de aprofundamento das avaliações.

\section{REFERÊNCIAS}

1. ARAÚJO, A. A. de. Principais gramíneas do Rio Grande do Sul. Livraria Sulina Editora. Porto Alegre, 1971. p. $196-197$.

2. COMISSÃO DE QUÍMICA E FERTILIDADE DO SOLO RS/SC - CQFS-RS/SC. Manual de adubação e de calegem para os Estado do Rio Grande do Sul e Santa Catarina. Port Alegre, SBCS/Núcleo Regional Sul, UFRGS, 2004. 400p.

3. CORSI, M; NASCIMENTO JR., D. Princípios de fisiologia e morfologia de plantas forrageiras aplicados ao manejo das pastagens. In: Pastagens: Fundamentos da Exploração Racional. Piracicaba: FEALQ, 1994. p. 15-48.

4. COSTA, K. A. de P.; OLIVEIRA, I.P.; FAQUINI, V. et al. Intervalo de corte na produção de massa seca e composição químico-bromatológica da Brachiaria brizantha cv. MG-5. Ciência e Agrotecnologia, v. 31, n. 4, p. 1197-1202, 2007.

5. DA SILVA, S.C.; PEDREIRA, C.G.S. Princípios de ecologia aplicados ao manejo de pastagem. In: SIMPÓSIO SOBRE ECOSSISTEMAS DE PASTAGENS, 3., Jaboticabal, 1997. Anais... Jaboticabal: Funep, 1997. p. 1-12.

6. DRUDI, A.; FAVORETTO, V. Influência da frequência, época e altura do corte na produção e na composição química do capim-andropógon. Pesquisa Agropecuária Brasileira, v. 22, n. 12, p. 1287-1292, 1987

7. EMPRESA BRASILEIRA DE PESQUISA EM AGROPECUÁRIA - EMBRAPA. Centro Nacional e Pesquisa em Solos. Sistema Brasileiro de Classificação de Solos. Brasília: Embrapa- SPI; Rio de Janeiro: Embrapa-Solos, 2006. 306p.

8. FRUPLANORTE Monitoramento e difusão de dados Agrometeorológicos em apoio à fruticultura no Planalto Norte Catarinense. Disponível em: http://www.ciram.com.br/MDA_Fruplanorte/index.jsp?url=home.jsp. Acesso em 04 de outubro de 2011.

9. HANISCH, A. L., GISLON, I. Massa de forragem e valor nutritivo de gramíneas perenes de inverno no Planalto Norte Catarinense. Scientia Agraria, v.11, n.1, p.25-32. 2010.

10. HANISCH, A.L.; CÓRDOVA, U.A.; FLARESSO, J.A.; ROSA, J.L. Comportamento produtivo de populações de capimlanudo em Santa Catarina. Agropecuária Catarinense. v.24, n.3, p.64-68, 2011.

11. MACARI, S.; ROCHA, M.G.; RESTLE, J. et al. Avaliação da mistura de cultivares de aveia preta (Avena strigosa) com azevém (Lolium multiflorum) sob pastejo. Ciência Rural, v.36, n.2, p.910-915, 2006.

12. MOLOFSKY, J., MORRISON, S. L.; GOODNIGHT, C. J. Genetic and environmental controls on the establishment of the invasive grass, Phalaris arundinacea. Biological Invasions, n.1: p.181-188, 1999.

13. OTERO, J. R. de. Informações sobre algumas plantas forrageiras. Ministério da Agricultura/Serviços de informação Agrícola. Rio de Janeiro, $2^{\mathrm{a}}$ Ed. 1961. 334p. (Série Didática, $\left.n^{\circ} 11\right)$.

14. PONTES, L. da S., SOUSSANA J.-F., LOUAULT, F., ANDUEZA, D., CARRĖRE P. Leaf traits affect the above-ground productivity and quality of pasture grasses. Functional Ecology, n.21, p. 844-853, 2007.

15. RAYMOND, W.F. The nutritive value of forage crops. Advances in Agronomy, v.21, p.1-108, 1969.

16. RUNCIMAN, D. J., LEE, A. M., REED, K. F. M., WALSH, J. R. Dicoumarol toxicity in cattle associated with ingestion of silage containing sweet vernal grass (Anthoxanthum odoratum). Australian Veterinary Journal, v. 80, n 1\& 2, 2002.

17. SANTOS, K. L. Influência de lâminas de irrigação e intervalos de corte sobre a produtividade da rebrota de Hermathria altissima. Universidade Federal de Santa Maria, Centro de Ciências Rurais, Programa de Pós-Graduação em Engenharia Agrícola, RS, 2009.

18. SCHEFFER-BASSO, S.M.; FÁVERO, F.; JOURIS, C.; DALL'AGNOL, M. Seleção de populações de Bromus auleticus: uma gramínea perene de inverno. Revista Brasileira de Zootecnia, v. 38, n.2, p. 249-255, 2009.

19. SCHEFFER-BASSO, S.M; SOARES, G.C.; DALL'AGNOL, M. Efeito da freqüência e altura de corte em dois genótipos de Bromus auleticus Trin. ex Ness. Revista Brasileira de Agrociência, v.8, p.191-194, 2002.

20. SILVA, D. J.; QUEIROZ, A. C. Análise de alimentos: métodos químicos e biológicos. 3. ed. Viçosa: UFV, 2002. 235 p.

21. SILVA, S.C. da; PEDREIRA, C.G.S. Princípios de ecologia aplicados ao manejo da pastagem. In: SIMPÓSIO SOBRE ECOSSISTEMAS DE PASTAGENS, 3. 1997, Jaboticabal. Anais... Jaboticabal: Funep, 1997. p. 1-62.

22. SOUZA, M.R.F.; PINTO, J.C.; OLIVEIRA, I.P. et al. Produção de forragem de capim-tanzânia sob intervalos de corte e doses de potássio. Ciência e Agrotecnologia, v.31, n.5, p. 1532-1536, 2007.

23. TILLEY, J.M.A.; TERRY, R.A. A two stage technique for the "in vitro" digestion of forage crop. Journal of Britain Grassland Society, v.18, p.104-111, 1963.

24. VIEIRA, A. C.; HADDAD, C.M.; CASTRO, F.G.F. et al. Produção e valor nutritivo da grama bermuda Florakirk [Cynodon dactylon (L.) pers.] em diferentes idades de crescimento. Scientia Agricola, v.56, n.4, p.1185-1191. 1999. 